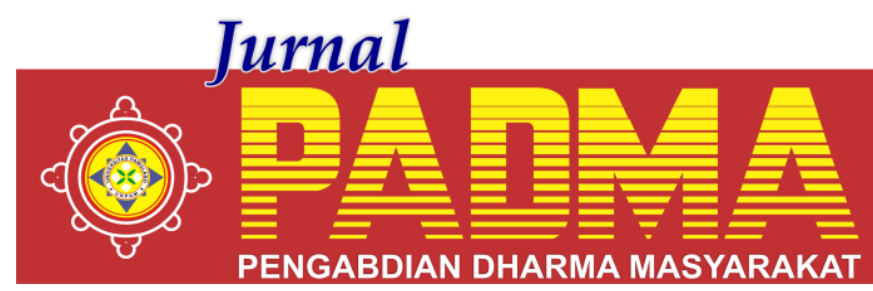

VOLUME 1, NOMOR 2, APRIL 2021

\title{
,PELATIHAN BEDAH SOAL PSIKOTES DALAM MENGHADAPI DUNIA KERJA PADA SISWA SMK DARUSSALAM PURI PAMULANG
}

\author{
${ }^{1 *}$ Indra Novendri, ${ }^{2}$ Demaz Adithya Widharma, ${ }^{3}$ Deyan Tiara Monika, ${ }^{4}$ Hikmatul Ulum \\ Alawiyah, ${ }^{5}$ Karina Mardhatillah, ${ }^{6}$ Hadi Supratikta, ${ }^{7}$ Agung Nugroho \\ Universitas Pamulang, Tangerang Selatan, Banten, Indonesia \\ *indranovendri8@gmail.com
}

\begin{abstract}
Abstrak
Pengabdian ini berjudul Pelatihan Bedah Soal Psikotes Dalam Menghadapi Dunia Kerja Pada Siswa SMK Darussalam Puri Pamulang. Tujuan umum dari kegiatan pengabdian kepada masyarakat ini adalah Memberikan pelatihan dan pengetahuan secara praktis bagi siswa SMK Darussalam Puri Pamulang agar siap menghadapi dunia setelah lulus. Metode yang digunakan adalah metode survey dan penyampaian materi secara langsung serta simulasi dan diskusi mengenai soal psikotes, serta tips tips dalam mengerjakan soal soal tersebut agar para siswa terbiasa menghadapi psikotes saat berada dalam dunia kerja. Kesimpulan dari pengabdian kepada masyakat ini adalah bahwa para siswa SMK Darussalam Puri Pamulang paham dan siap untuk terjun langsung dalam tes sesungguhnya.
\end{abstract}

Kata Kunci: Bedah Soal, Pemahaman Siswa, Persiapan Siswa

Abstract

This dedication was entitled Training on Psychological Test Questions in Facing the World of Work for the Students of SMK Darussalam Puri Pamulang. The general purpose of this community service activity is to provide practical training and knowledge for students of SMK Darussalam Puri Pamulang so that they are ready to face the world after graduation. The method used is the survey method and the delivery of material directly as well as simulation and discussion of psychological test questions, as well as tips on working on these questions so that students are accustomed to facing psychological tests while in the world of work. The conclusion of this community service is that the students of SMK Darussalam Puri Pamulang understand and are ready to take the real test directly.

Keywords: Problem Surgery, Student Understanding, Student Preparation

\section{PENDAHULUAN}

Menurut Undang-Undang No. 20 Tahun 2003 Pendidikan adalah usaha sadar dan terencana untuk mewujudkan suasana belajar dan proses pembelajaran agar peserta didik secara aktif mengembangkan potensi dirinya untuk memiliki kekuatan spiritual keagamaan, pengendalian diri, kepribadian, kecerdasan, akhlak mulia, serta ketrampilan yang diperlukan dirinya, masyarakat, bangsa dan negara.

Makna pendidikan secara sederhana dapat diartikan sebagai usaha manusia untuk membina kepribadiannya sesuai dengan nilai-nilai di dalam masyarakat dan kebudayaannya. Dengan demikian, bagaimanapun sederhananya peradaban suatu masyarakat, di dalamnya terjadi atau berlangsung suatu proses pendidikan. Karena itulah sering dinyatakan pendidikan telah ada sepanjang peradaban umat manusia. Pendidikan pada hakikatnya merupakan usaha manusia melestarikan hidupnya.

Menteri Perencanaan Pembangunan Nasional (PPN)/ Kepala Badan Perencanaan Pembangunan Nasional (Bappenas) Bambang Brodjonegoro menilai ada anomali terhadap penyerapan tenaga kerja di Indonesia. Ini lantaran lulusan Sekolah Menengah Kejuruan (SMK) lebih banyak menganggur dibanding Sekolah Menengah Atas (SMA). Bambang mengacu pada data Badan Pusat Statistik (BPS) per Agustus 2018 yang menunjukkan Tingkat Pengangguran Terbuka (TPT) Indonesia sebesar 6,99 juta orang, atau 5,34 persen dari jumlah angkatan kerja sebanyak 131,01 juta jiwa. Dari jumlah tersebut, lulusan SMK menganggur tercatat 11,24 persen, 
sementara lulusan SMA menganggur mengambil porsi 7,95 persen. Menurut Bambang kondisi ini terbilang tak masuk akal. Sebab, lulusan SMK harusnya bisa lebih mudah mendapatkan pekerjaan karena dibekali kompetensi dan keterampilan yang mumpuni dibandingkan SMA.

Badan Pusat Statistik (BPS) mencatat jumlah pengangguran terbuka pada Agustus 2019 berjumlah 7,05 juta orang, meningkat dari Agustus 2018 yang hanya 7 juta orang. Dalam paparannya, Kepala Badan Pusat Statistik Suhariyanto mengatakan, tingkat pengangguran terbuka (TPT) didominasi oleh lulusan Sekolah Menengah Kejuruan (SMK) sebesar 10,42 persen pada Agustus 2019. "Tingkat pengangguran tertinggi adalah mereka yang berpendidikan SMK," kata Kepala BPS Suhariyanto di Jakarta, Selasa (5/11/2019). Oleh karenanya, ia berkesimpulan bahwa manajemen SMK di Indonesia masih kurang baik.

Interview, rekrutmen, psikotes, dan para peamar dari berbagai latar belakang pendidikan sudah menjadi aktivitas rutin setiap hari. Proses panjang ini pastinya sangat melelahkan bagi semua pencari kerja. Mau tidak mau, sesulit apapun tes di jalani, walau berkali kali gagal dalam tahap seleksi, para pelamar seolah tidak putus putusnya datang. Merekrut dan menyeleksi calon karyawan semakin sulit belakangan ini. Kenyataannya, tamatan SMK sekarang ini benar-benar belum siap kerja. Mata pelajaran yang tercantum pada daftar nilai di ijazah bisa jadi hanya sebatas teori kejuruan.

Berdasarkan penjelasan diatas, dapat diketahui bahwa para siswa SMK tidak siap untuk memasuki dunia kerja. Bedah soal psikotes ini sangat diperlukan dilakukan untuk memperkenalkan dan agar para siswa tebiasa dalam mengerjakan soal soal psikotes ketika rekrutmen. Oleh sebab itu, pelatihan bedah soal psikotes seperti ini seharusnya dijadikan pelatihan yang penting bagi para siswa untuk meningkatkan kemungkinan lolos dalam tahap seleksi rekrutmen dan mengurangi angka pengangguran yang didominasi oleh lulusan SMK.

\section{METODE}

Metode pelatihan yang diterapkan berdasarkan solusi atas permasalahan di
SMK Darussalam Puri Pamulang Pengabdian Kepada Masyarakat (PKM) akan dilaksanakan di Otista No.36 RT 01, RW 10 Kelurahan Ciputat Kecamatan Ciputat, Kota Tangerang Selatan Provinsi Banten pada bulan November 2020, sebagai berikut :

Metode Pelatihan : yang dirancang untuk mengembangkan sumber daya manusia melalui rangkaian kegiatan identifikasi, pengkajian serta proses belajar yang terencana. Untuk mengatasi permasalahan yang ada, tim akan melakukan pelatihan-pelatihan bagi seluruh siswa. Adapun metode pelatihannya dengan mengumpulan para siswa di sekolah, pembagian soal lalu dilanjutkan dengan pembahasan serta bedah tuntas kunci jawaban dan tips tips dalam mengerjakan soal psikotes.

Rencana kegiatan yang akan dilakukan untuk kegiatan ini:

a. Tahap persiapan, Persiapan ini difokuskan dengan menyiapkan semua peralatan yang dibutuhkan untuk melaksanan kegiatan ini, studi literatur dan melakukan koordinasi dengan instansi terkait untuk melakukan kegiatan bedah soal psikotes dalam upaya mewujudkan kesiapan menghadapi dunia kerja para siswa SMK Darussalam Puri Pamulang di Otista No.36 RT 01, RW 10 Kelurahan Ciputat Kecamatan Ciputat, Kota Tangerang Selatan Provinsi Banten.

b. Penentuan Lokasi, Pada tahap ini dilakukan kunjungan ke lokasi untuk menentukan tempat (lokasi) pendampingan serta pelatihan bedah soal psikotes dalam upaya mewujudkan kesiapan menghadapi dunia kerja para siswa SMK Darussalam Puri.

c. Perancangan sistem pengerjaan soal dan dalam upaya dan strategi mewujudkan para siswa SMK Darussalam Puri Pamulang dapat menyelesaikan proses seleksi dengan baik.

Metode Kegiatan PKM ini dengan cara diskusi dan tanya jawab seputar cara mengerjakan soal dan tips tips mengerjakan soal psikotes agar dapat seelesai dengan baik.

\section{HASIL DAN PEMBAHASAN}

Pada dasarnya siswa SMK dibentuk sebagai tenaga ahli yang siap kerja. 
Pendidikan vokasi seperti sekolah menengah kejuruan (SMK) dipersiapkan agar para siswa bisa terjun langsung ke dunia kerja usai mereka lulus. Dengan begitu, akan semakin banyak Sumber Daya Manusia (SDM) yang produktif di dunia kerja.

Berdasarkan data dari Kementerian Pendidikan dan Kebudayaan (Kemdikbud), terdapat 4,4 juta siswa SMK yang bisa menjadi generasi siap kerja. Tenaga kerja itulah yang dibutuhkan oleh pemerintah untuk mewujudkan visi ekonomi digital dengan cepat.

Dari hasil pelaksanaan kegiatan pengabdian pada masyarakat tersebut, dapat dikatakan jika kegiatan pelatihan bedah soal psikotes pada siswa SMK Darussalam Puri Pamulang tersebut cukup berhasil. Hal ini terlihat dari antusiasme, proses kegiatan pengerjaan soal psikotes dan pemahaman sesudah mengikuti pelatihan bila dibandingkan dengan pemahaman mereka mengenai materi tersebut sebelumnya. Data tersebut dapat dilihat pada tabel penilaian materi bedah soal psikotest. Selain itu, evaluasi para peserta juga menunjukkan hasil yang positif mengingat semua siswa mengerjakan soal psikotes hingga selesai yang mengindikasikan jika peserta cukup puas dan antusias dengan proses penyampaian materi yang dilakukan oleh narasumber. Adapun untuk ke depannya, akan lebih baik jika penyuluhan yang dilakukan mencakup aspek penting lain yang juga dibutuhkan oleh siswa SMK di dunia kerja, misalnya bagaimana berkomunikasi yang baik untuk semua jenjang serta bagaimana berempati terutama bagi mereka yang fokus pada pekerjaan-pekerjaan yang membutuhkan pertemuan dengan banyak orang.

Adapun dokumentasi kegiatan sebagai berikut:

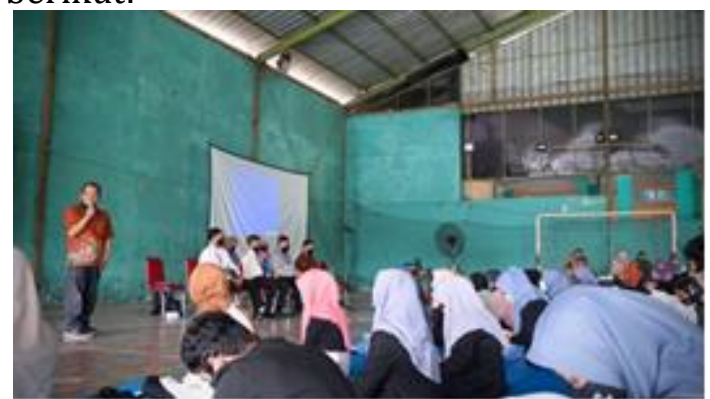

Gambar 1. Sambutan Dosen Program Pasccasarjana Universitas Pamulang sekaligus Dosen Pendamping PKM Bpk. Drs. Hadi Supratikta, M.M di SMK Darussalam

Puri Pamulang 11 November 2020

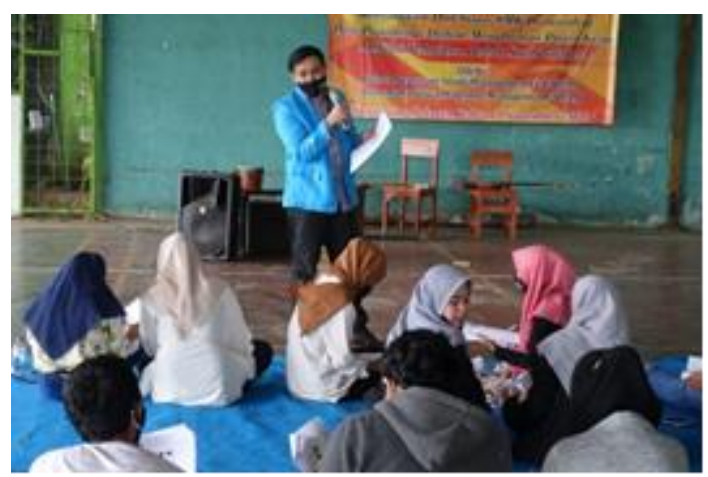

Gambar 2. Team PKM mahasiswa program pasccasarjana Unpam, memberikan materi PKM (Pengabdian Kepada Masyarakat)

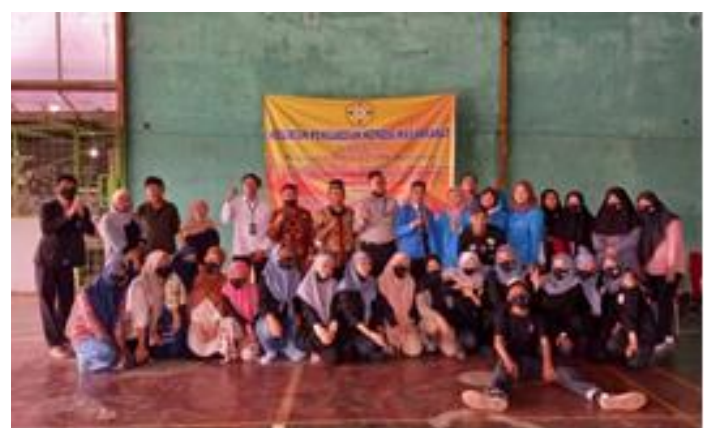

Gambar 3. Foto bersama seluruh siswa SMK Darussalam Puri Pamulang yang mengikuti pelatihan psikotes dan dosen Unpam serta Mahasiswa Pascasarjana Unpam

\section{PENUTUP}

\section{Kesimpulan}

1. Berdasarkan PKM yang telah dilakukan SMK Darussalam Puri Pamulang, maka dapat disimpulkan bahwa para siswa membutuhkan pelatihan bedal soal psikotest, khususnya logika aritmatika dan untuk meningkatkan kemampuan para siswa dalam mengerjakan soal psikotest yang lain.

2. Setelah dilakukan pelatihan bedah soal psikotest kepada para siswa SMK Darussalam Puri Pamulang, maka dapat disimpulkan para siswa menjadi lebih memahami cara dan trik dalam mengerjakan soal-soal psikotest.

3. Berdasarkan tabel hasil penilaian materi bedah soal psikotest dapat disimpulkan bahwa para siswa dapat dikatakan cukup siap untuk memasuki dunia kerja dan cukup siap menghadapi soal-soal 
psikotest yang akan diberikan oleh pihak perusahaan yang mencari tenaga kerja.

\section{DAFTAR PUSTAKA}

Akmal, Sari Zakiah dkk. "Program Penyuluhan Persiapan Memasuki Dunia Kerja Bagi Siswa SMK N 13 Jakarta". Jurnal PKM : Pengabdian Kepada Masyarakat. Jakarta: Universitas Yarsi. 2019.

M Catio, D Sunarsi. (2020). Analisa Pengaruh Kompetensi, Disiplin Kerja Dan Motivasi Terhadap Kinerja Guru Pada SMK Sasmita Jaya 1 Pamulang Kota Tangerang Selatan. Equilibrium: Jurnal Penelitian Pendidikan dan Ekonomi 17 (02), 16-26

Cheryl. 2015. Tamatan SMK, SDM Tidak Siap Pakai. Diakses dari https://www.kompasiana.com/lisache ryl/552ac3e3f17e61b73cd623bb/tam atan-smk-sdm-tidak-siap-pakai, pada 14 November 2020.

CNN Indonesia. 2019. Lulusan SMK Banyak Menganggur. Diakses dari https://www.cnnindonesia.com/ekon omi/20190403134803-92-

383168/lulusan-smk-banyakmenganggur-menteri-bambanganggap-anomali, pada 14 November 2020.

Handoko, T Tani. Manajemen edisi 2. Yogyakarta: BPFE-Yogyakarta. 2012

Hikmayani. 2018. Mendongkrak Partisipasi Kerja Lulusan SMK. Diakses dari https://news.detik.com/kolom/d4302979/mendongkrak-partisipasikerja-lulusan-smk, pada 14 November 2020.

John, Dewey. 2019. Pengertian Pendidikan Dan Makna Pendidikan Menurut Para Ahli. Diakses dari https://www.silabus.web.id/pengertia n-pendidikan-dan-makna-pendidikan/, pada 14 November 2020.

Kompas.com.2019. BPS: Pengangguran Meningkat, Lulusan SMK Mendominasi. Diakses dari https://money.kompas.com/read/201 9/11/05/155358926/bpspengangguran-meningkat-lulusansmk-mendominasi, pada 14 November 2020.
Nawawi, Hadari. Manajemen Sumber Daya manusia: Untuk Bisnis Yang Kompetitif. Yogyakarta: Gadjah Mada University Press. 2011

Potale, Billy Renaldo dkk. "Pengaruh Proses Rekrutmen Dan Seleksi Terhadap Kinerja Karyawan Pada PT Bank Sulutgo". Vol. 16 No. 04. Manado: Universitas Sam Ratulangi.2016

Pratomo, Devanto Shasta. "Fenomena Pengangguran Terdidik Di Indonesia". Purwokerto: Universitas Brawijaya. 2017

Putra, Dwi Aditya. 2018. Siapkan Tenaga Kerja Siap Pakai, SMK Perlu Lakukan Upaya Ini. Diakses dari https://www.liputan6.com/bisnis/rea d//siapkan-tenagasmklakukan-upayaini, pada 15 November 2020.

Rochmanudin dan Saepudin. "Kiat Sukses Psikotes \& Wawancara Kerja Interview Untuk SMK".Yogyakarta: Paramitra Publishing. 2010.

Satryawati dan Wa Ode Saniah. "Peranan Tes Psikologi Terhadap Penempatan Pegawai Pada Politeknik Negeri Semarang". Vol.8 No.2 Agustus 2012. ISSN: $\quad$ 0216-6437. Samarinda: Politeknik Negeri Samarinda. 2012.

Setiawan, Yuli. 2016. 4,4 Juta Siswa SMK Harus Jadi Generasi Siap Kerja. Diakses dari http://psmk.kemdikbud.go.id/konten/ 1830/44-juta-siswa-smk-harus-jadigenerasi-siap-kerja, pada 15 November 2020.

Sugiyanto. Studi Kelayakan Bisnis. Tangerang Selatan: YPSIMBanten.2020

Tarwijo. "Pengaruh Rekrutmen, Seleksi Dan Motivasi Terhadap Kinerja Karyawan Pada Toko Buku Gramedia Cinere". Vol.2 No.1 November 2018. ISSN: 2598-9545. Pamulang: Universitas Pamulang. 2018

Y Kadarusman, D Sunarsi. (2020). Pengaruh Strategi Penetapan Harga Terhadap Peningkatan Jumlah Siswa Pada SMK PGRI Balaraja. JS (JURNAL SEKOLAH) 4 (3), 213-221 